\title{
Material Properties of Firefighter Ladder Composed from AA6063 and Few Other Aluminium-Based Alloys
}

\author{
Klára Hosová, Jiř́ Kubásek, Markéta Straková, David Nečas \\ University of Chemistry and Technology, Faculty of Chemical Technology, Department of Metals and Corrosion \\ Engineering, Technická 5, 166 28, Praha 6 -Dejvice, Czech Republic, E-mail: hosovak@vscht.cz
}

The sectional fire ladders, made of aluminium alloy AA6063, belong to the basic equipment of the fire department of the Czech Republic. The use of these materials facilitates the deployment of ladders for firefighting, but it also brings with it certain pitfalls. During the use of ladders in extinguishing fires, their thermal influence and subsequent changes in mechanical properties may occur. This is highly dangerous and can lead to people falling from these ladders due to a significant reduction in the mechanical properties of the material.

Keywords: Aluminium, firefighter ladder, microstructure, mechanical properties

\section{Introduction}

Firefighter ladders are generally used during the intervention of firefighters except for transport of rescued person. They are mainly applied for ascents to higher places or, conversely, for descents into depressions. Furthermore, they can be used to distribute the weight during a rescue on the frozen water area, etc. Failure of the strength of the ladder can have fatal consequences, and therefore it is necessary to check the quality by a standard test. Such test is defined by the standard ČSN EN 1147 "Portable ladders for fire service use". It has been shown repeatedly that the test is not sufficiently conclusive from a safety point of view.

The standard ČSN EN 1147 defines non-destructive as well as destructive testing of fire ladders. The aim is to focus on the non-destructive flexion test defined by this standard. In this test, the ladder placed on 2 supports, one of which is fixed and the other sliding. The supports are located $20 \mathrm{~cm}$ from the edges of the ladder. During the test, the weight is placed in the centre of the ladder and the flexion of the ladder is measured. This is repeated once more with a heavier weight. Subsequently, the weights are removed and the deflection of the ladder is measured. Indication of plastic deformation means the failure of the test and inappropriate mechanical properties of the ladder. The problem with this standard is that it can not reliably estimate the immediate decrease in the mechanical properties of a ladder.

Aluminium alloys are widely used mainly due to their combination of mechanical and corrosion properties. In particular, the aluminium alloys of the 6xxx series (Al-Mg-Si) are used for various application in the automotive industry and for sports equipment [1]. The alloy AA6063 is most often used for the production of firefighter ladders. This alloy excels in high strength compared to low weight, good corrosion resistance, weldability, formability and is suitable for anodizing [2-3].

The main alloying elements of the are magnesium and silicon. The ratio of these elements has a major influence on the formation of precipitates [3]. An excess of one of them affects the properties of the material. Increasing the Si concentration supports the formation of fine-grained precipitates, which results in higher alloy strength. Increasing the $\mathrm{Mg}$ concentration improves the corrosion resistance, but also results in a decrease in the strength of the alloy [4].

Aluminium alloy 6063 is widely used to produce components by extrusion [5]. The vast majority of extruded profiles are used for constructions [6-7]. After extrusion processes, the material is generally aged using temperatures up to $200^{\circ} \mathrm{C}$. Precipitation hardening by $\mathrm{Mg}_{2} \mathrm{Si}$ is observed during ageing [8-9]. This intermetallic compound improves the mechanical and corrosion properties of the alloy [5-6, 9]. The chemical composition of firefighter ladder material can often vary depending on the specific supplier.

When alloy 6063 is exposed to the increased temperature or even the flames, it is thermally affected and the mechanical properties may be significantly changed [8].

The purpose of the presented paper is to describe the microstructure and mechanical properties of the selected type of the firefighter ladder to show differences in properties in various components and therefore reveals possible weaker spots for material destruction.

\section{Material and experiment}

The selected ladder is made of commercial alloy AA6063. The ladder was composed of several metallic components including beams, steps, ladder locks and 
welds. The illustration of ladder parts is in Fig. 1. Ladder locks are welded to the beams by the method TIG
(Tungsten Inert Gas) with the additional melting electrode.

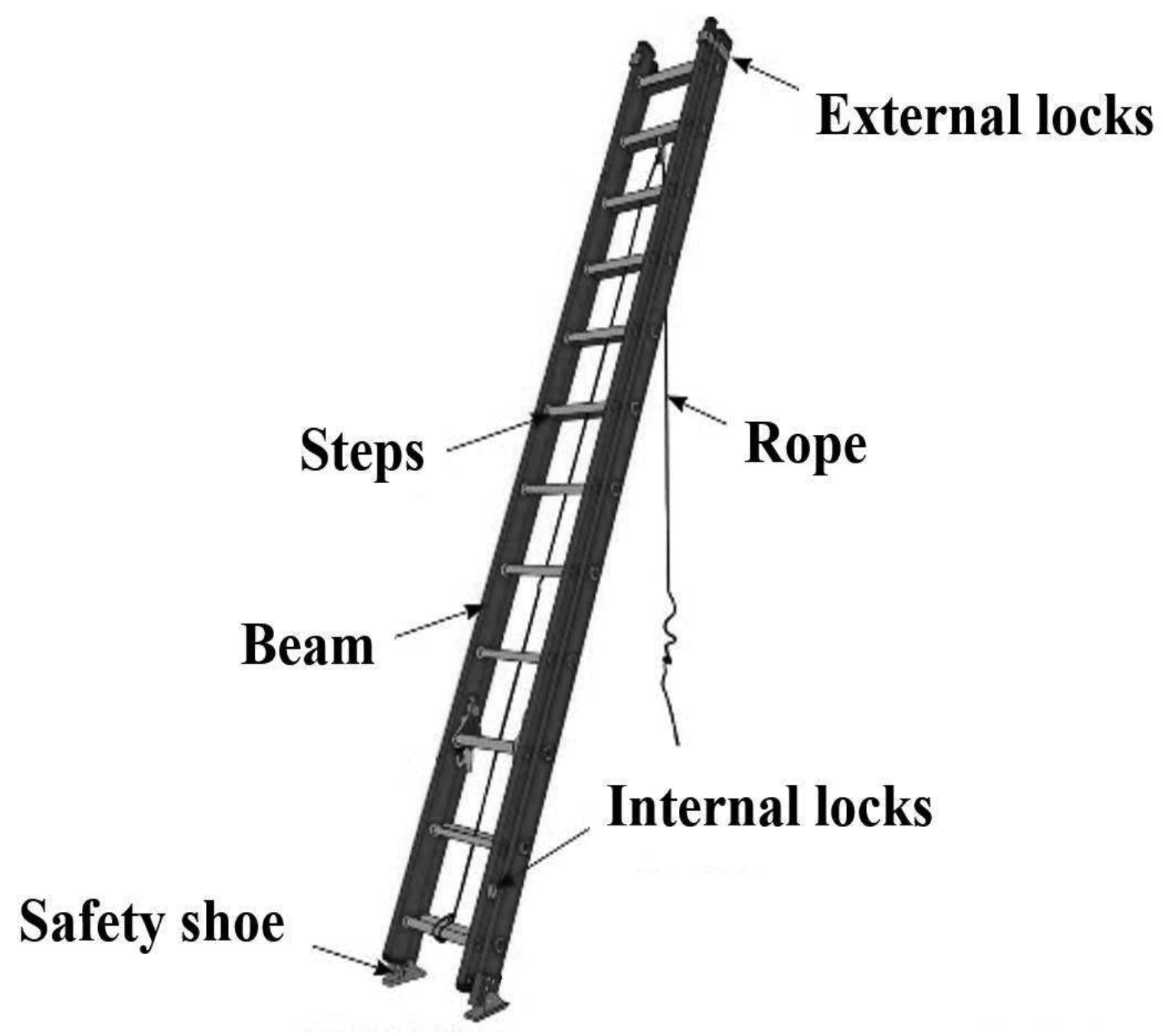

Fig. 1 Description of the one part of the sectional ladder [10].

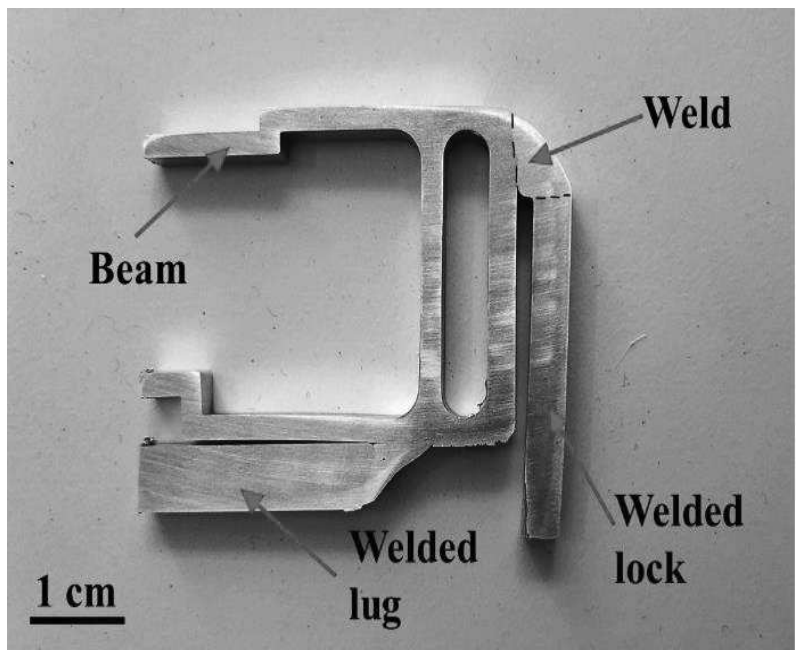

Fig. 2 Cross-section of the ladder beam - one half.

The cross-section of the ladder beam is displayed in Fig. 2.
2.1 Chemical compositionThe chemical composition of a ladder beam was determined using a glow discharge optical emission spectrometer (GD-OES) (Atomic emission spectrometer Horiba Jobin Yvon GD Profiler II). Other parts were analysed by an energy dispersive spectrometry (EDS) using a scanning electron microscope (SEM - Tescan Vega3 LMU). The results of the composition of ladder beams are shown in Tab. 1 The standardized composition of alloy AA6063 is displayed for comparison.

\subsection{Heat treatment}

Samples taken from the beam of firefighter ladders were annealed in a resistance furnace, in terms of a simulation of the heat exposure during the fire. The heat treatment was running at temperatures of $200^{\circ} \mathrm{C}$ and $300{ }^{\circ} \mathrm{C}$. The samples were annealed for 2 hours in the air. After removing the samples from the furnace, they were cooled in the air. 
Tab. 1 Chemical composition of aluminium alloy 6063.

\begin{tabular}{lllll} 
& $\begin{array}{l}\text { AA6063 } \\
\text { standard } \\
\text { ČSN EN 573-3 }\end{array}$ & Ladder & & \\
& & Beam & Ladder lock & Weld \\
Element & [wt. \%] & [wt. \%] GD-OES & [wt. \%] GD-OES & [wt. \%] EDS \\
\hline $\mathrm{Mn}$ & $\leq 0.10$ & 0.04 & 0.08 & - \\
$\mathrm{Fe}$ & $\leq 0.35$ & 0.19 & 0.15 & 0.2 \\
$\mathrm{Mg}$ & $0.45-0.90$ & 0.48 & 2.56 & 4.3 \\
$\mathrm{Si}$ & $0.20-0.60$ & 0.45 & 0.07 & 0.1 \\
$\mathrm{Zn}$ & $\leq 0.10$ & 0.03 & 0.22 & - \\
$\mathrm{Ti}$ & $\leq 0.10$ & 0.02 & 0.03 & - \\
$\mathrm{Cr}$ & $\leq 0.10$ & 0.04 & 0.16 & - \\
$\mathrm{Cu}$ & $\leq 0.10$ & 0.01 & 0.01 & - \\
$\mathrm{Other}($ each) & $\leq 0.05$ & $\leq 0.01$ & - & Rest \\
Other (all) & $\leq 0.15$ & 0.01 & - & \\
$\mathrm{Al}$ & Rest & Rest & Rest & \\
\hline
\end{tabular}

\subsection{Microstructure characterization}

The microstructure was characterized in the crosssection through the beam. The samples were ground on grinding papers with a roughness of P800 - P4000. The polishing was performed with a diamond paste D3 and D2 and on polishing cloth using Eposil F suspension. The samples were etched in Keller's reagent ( $2 \mathrm{ml} \mathrm{HF}, 3 \mathrm{ml} \mathrm{HCl}, 5 \mathrm{ml} \mathrm{HNO} 3,190 \mathrm{ml} \mathrm{H} 2 \mathrm{O}$ ). The microstructure was characterized by optical microscope (Olympus PME3) and scanning electron microscope (Tescan Vega3 LMU) with EDS (Oxford Instruments - Aztec), equipped with an electron backscatter diffraction (EBSD). The grain size was defined using the Image J program from the optical microstructure images. Images from EBSD analysis were processed using Channel V software.

\subsection{Mechanical properties}

Vickers hardness (HV1) was measured on the cross-section of the ladder beam in the initial state and after selected annealing.

Besides, tensile tests on samples obtained from the ladder beam were performed at laboratory temperature, 100,150 and $200{ }^{\circ} \mathrm{C}$. These tests were performed on a LabTest 5.250SP1-VM machine according to the standard ČSN EN ISO 6892-1. Samples for mechanical strength testing were taken from the longitudinal part of the ladder beam. The sample length of the test area was $75 \mathrm{~mm}$ and the thickness $12.5 \mathrm{~mm}$. The end of the sample was intended for fixing to the prismatic jaws of the testing machine and the width in this area reached $15 \mathrm{~mm}$.

\section{Results and discussion}

\subsection{Microstructure}

Fig. 3 shows the microstructure on the interface of beam material and weld. The microstructures for the material in initial conditions and after annealing at higher temperatures are compared. The microstructure of weld is different from the basic material of the beam. This is due to the different composition of the material, as already indicated in Tab. 1.

A heat affected zone is visible between the microstructure of the beam and the weld. Weld is composed of primary $\alpha-\mathrm{Al}$ solid solution and secondary phases at the dendritic interface. The dark spots in Fig. 3 indicate secondary phases. These phases are characterized by an increased amount of $\mathrm{Mg}$ and correspond to the $\mathrm{Al}_{3} \mathrm{Mg}_{2}$ phase (Fig. 4). The heat-affected zone contained both $\mathrm{Al}_{3} \mathrm{Mg}_{2}$ phase and $\mathrm{AlFeSi}$ phase. N. Yamamoto et al. [11] also reported the formation of intermetallic phase $\mathrm{Al}_{3} \mathrm{Mg}_{2}$ in the heat-affected zone of welded $\mathrm{Al}$ alloy. 


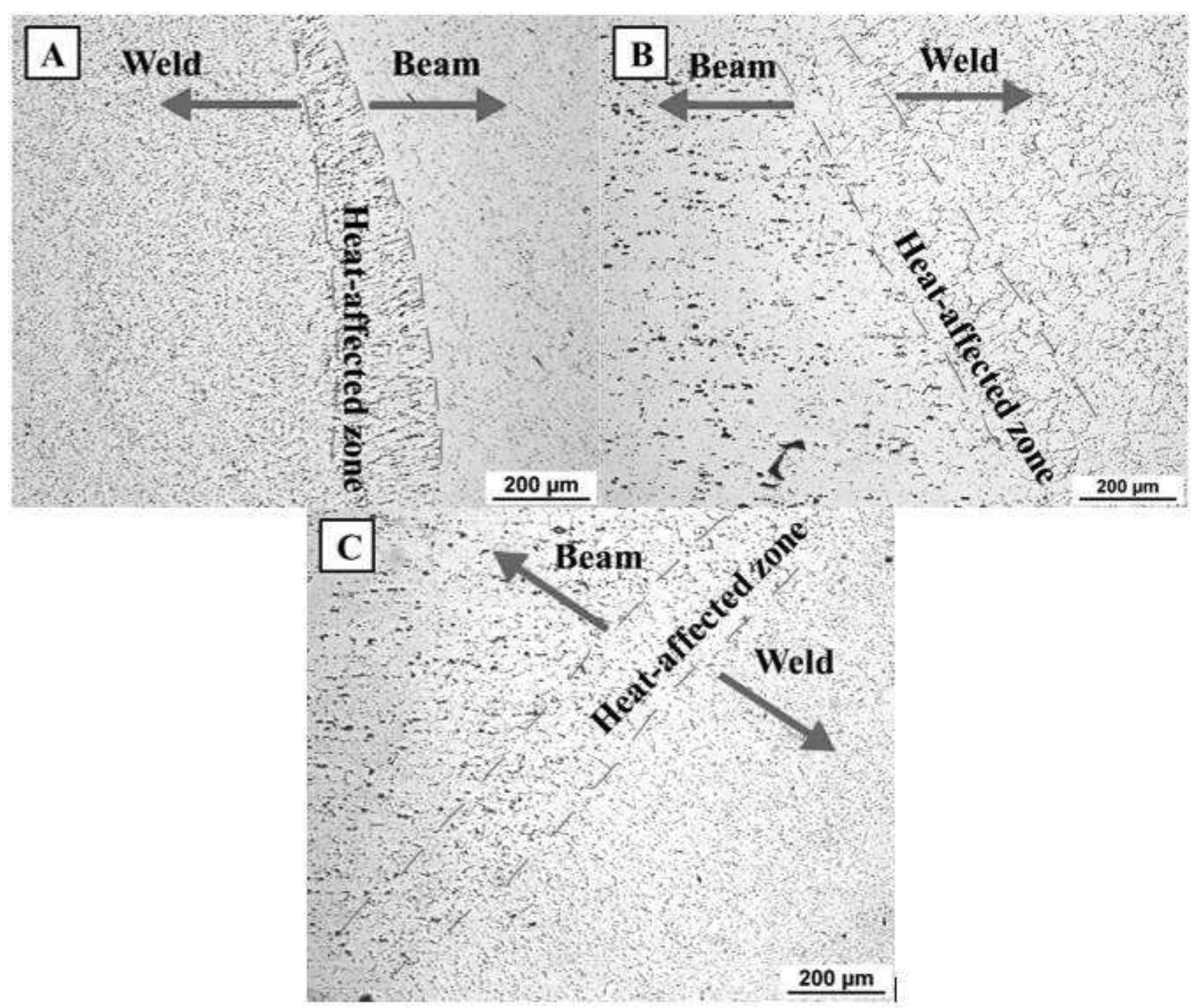

Fig. 3 Cross-section of material A) basic material of beam; B) annealed to $200^{\circ} \mathrm{C}$; C) annealed to $300^{\circ} \mathrm{C}$.
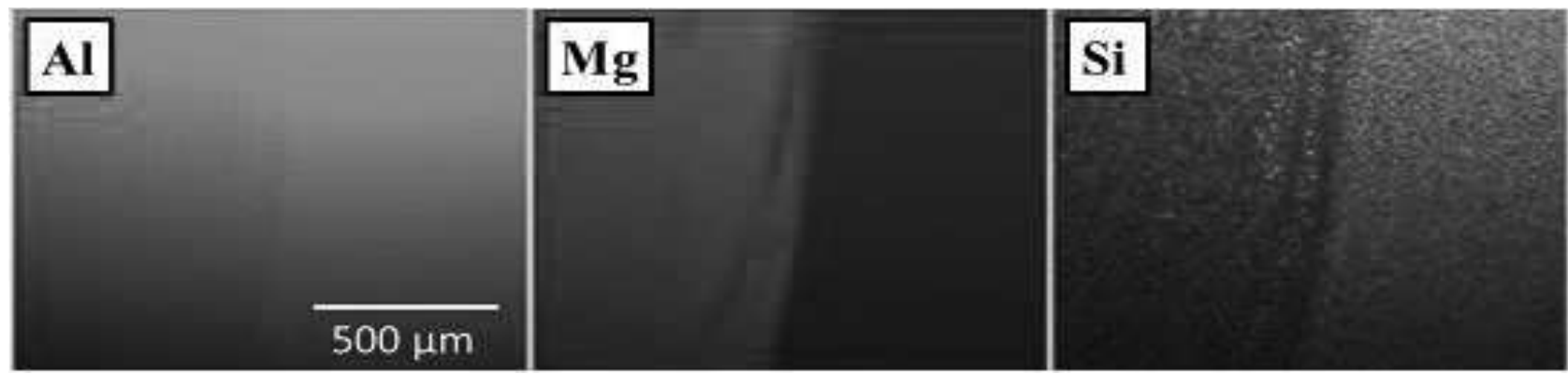

Fig. 4 Distribution of elements at the interface of the ladder beam (right side) and weld (left side).

Ladder beam is composed of a solid solution of magnesium and silicon in aluminium. Intermetallic phases such as AlFeSiMn and AlFeSi appear in the alloy according to the EDS analysis. In article by M. Shakoori Oskooie et al. [12] were visible fine precipitates which are located both within the $\mathrm{Al}$ grains and on the grain boundaries. The analysis indicated that the particles are $\mathrm{Mg}_{2} \mathrm{Si}, \mathrm{AlFeSi}$ or $\mathrm{Al}_{8} \mathrm{Mg}_{3} \mathrm{FeSi}_{2}$ [12]. These phases have a positive effect on the yield strength of the material but can harm the resulting ductility. The size of these phases was in the range of few $\mu \mathrm{m}$. The average grain size of the material of the beam was $49 \pm 30 \mu \mathrm{m}$. The largest measured grain size was $178 \mu \mathrm{m}$.

The microstructure of materials annealed at $200{ }^{\circ} \mathrm{C}$ and $300{ }^{\circ} \mathrm{C}$ observed using OM (optical microscopy) is shown in Fig. 3B and Fig. 3C. The neglectable change in the grain size of the material of the beam was observed during the annealing at $200{ }^{\circ} \mathrm{C}$. However, the grains more significantly coarsened at $300{ }^{\circ} \mathrm{C}$ 
up to the average value $61 \pm 35 \mu \mathrm{m}$. Especially increased occurrence of grains with a size above $100 \mu \mathrm{m}$ was recorded.

In Fig. 5 an inverse pole figure map (IPF) of microstructure obtained using electron backscattered diffraction method (EBSD) is displayed. Heat affected zone between weld and beam with specific elongated grains in the direction of the heat gradient is evident. It is also evident that recrystallized grains in the right side of Fig. 5 are textured with 001 direction parallel to the axis of the beam. This is a consequence of extrusion which is used during the manufacturing of these parts. On the contrary, the left side of Fig. 5 represents microstructure of the weld which is characterized by randomly oriented grains.

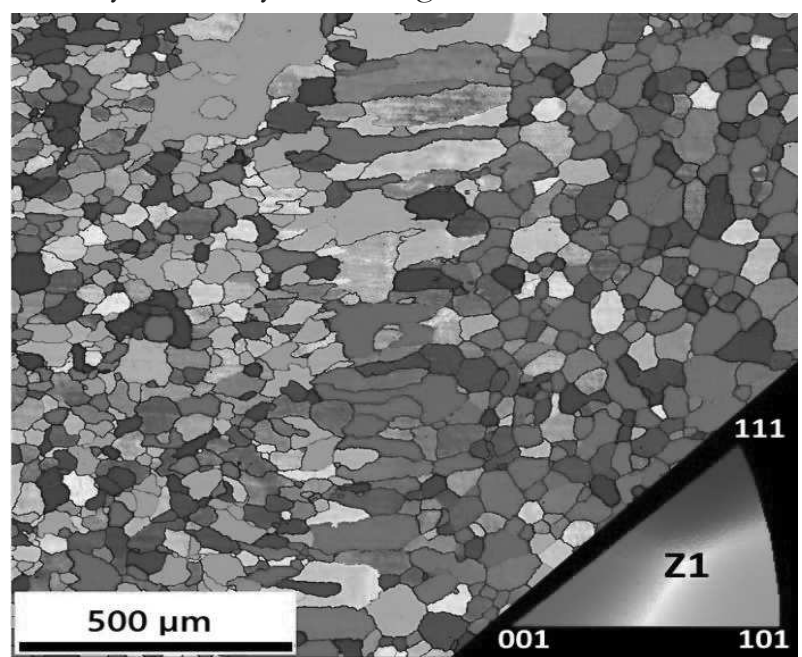

Fig. 5 IPF map obtained using EBSD (basic material). Z1 axis is parallel to the axis of beam.

\subsection{Hardness}

The hardness was measured in the entire profile of the ladder beam. It was found that the individual areas of the material had different hardness values. Areas of various hardness values are graphically illustrated in Fig. 6.



Fig. 6 Color representation of the areas with similar hardness values on the cross-section of the ladder beam.

The yellow area shows the measurement of the hardness of the original beam, the orange area represents heat-affected zone by weld, the red area represents weld and the green area shows the ladder locks. Differences in hardness are attributed to the different chemical composition of the individual components and also probably to various processing of these components. The measured hardness values are summarized in the following Tab. 2.

Tab. 2 Hardness of areas in Fig. 6.

\begin{tabular}{llll}
\hline Heat treatment & $\begin{array}{l}\text { Beam [HV1] } \\
\text { (yellow) }\end{array}$ & $\begin{array}{l}\text { Ladder lock [HV1] } \\
\text { (green) }\end{array}$ & $\begin{array}{l}\text { Weld [HV1] } \\
\text { (red) }\end{array}$ \\
\hline- & $70 \pm 11$ & $57 \pm 7$ & $69 \pm 7$ \\
$200{ }^{\circ} \mathrm{C} / 2 \mathrm{~h}$ & $83 \pm 6$ & $57 \pm 2$ & $78 \pm 8$ \\
$300{ }^{\circ} \mathrm{C} / 2 \mathrm{~h}$ & $42 \pm 1$ & $54 \pm 2$ & $56 \pm 12$ \\
\hline
\end{tabular}

In the vicinity of the weld (orange area in Fig. 6) the hardness values of the original materials (beam, lock) is decreased due to a large heat-affected zone around the weld. The high welding temperature caused the coarsening of the grains and also the formation of the casted microstructure compared to the relatively fine recrystallized microstructure of extruded beams. Generally, the hardness of the material in various areas does not decrease after annealing at $200{ }^{\circ} \mathrm{C}$. Instead, a slight increase may be observed for components like beam and ladder lock. Such an increase is attributed to the ageing process which can be active at $200{ }^{\circ} \mathrm{C}$. This suggests that specified parts of the original ladder are in underaged conditions. Similar behaviour of aluminium alloy was presented in the article by J. Kubásek et al. [13]. A significant decrease in HV1 is observed after annealing at $300{ }^{\circ} \mathrm{C}$ especially for the components like beam and ladder lock. This is caused by microstructure coarsening (Fig. 4) and also by coarsening of precipitates and intermetallic phases. An almost neglectable decrease in HV1 after annealing was observed for ladder lock. This component is prepared from an alloy containing about $2.5 \mathrm{wt} . \%$ of $\mathrm{Mg}$. The higher amount of intermetallic phases containing $\mathrm{Mg}$ probably stabilize the microstructure and suppress the decrease of mechanical properties after exposure to the elevated temperatures.

\subsection{Tensile test}

Stress-strain curves for tensile tests of samples which were cut from the ladder beam are displayed in Fig. 7. The TYS (tensile yield strength) and UTS (ultimate tensile strength) evaluated from these measurements are shown in Tab. 3. 
Tab. 3 TYS and UTS of ladder beam.

\begin{tabular}{llll}
\hline $\begin{array}{l}\text { Testing at a specific } \\
\text { temperature }\end{array}$ & $\begin{array}{l}\text { Heat treatment of } \\
\text { material from beam }\end{array}$ & TYS [MPa] & UTS [MPa] \\
\hline $25^{\circ} \mathrm{C}$ & - & $236 \pm 3$ & $264 \pm 2$ \\
$25^{\circ} \mathrm{C}$ & $200{ }^{\circ} \mathrm{C} / 2 \mathrm{~h}$ & $219 \pm 2$ & $242 \pm 3$ \\
$25^{\circ} \mathrm{C}$ & $300{ }^{\circ} \mathrm{C} / 2 \mathrm{~h}$ & $75 \pm 3$ & $131 \pm 3$ \\
$100{ }^{\circ} \mathrm{C}$ & - & $214 \pm 3$ & $225 \pm 4$ \\
$150^{\circ} \mathrm{C}$ & - & $195 \pm 4$ & $208 \pm 3$ \\
$200{ }^{\circ} \mathrm{C}$ & - & $167 \pm 2$ & $170 \pm 1$ \\
\hline
\end{tabular}

After annealing at $200{ }^{\circ} \mathrm{C}$, there was no significant change in terms of tensile properties compared to the initial state of the material. However, annealing at 300 ${ }^{\circ} \mathrm{C}$ led to significant degradation of both the yield strength and the tensile strength of the material (Fig.

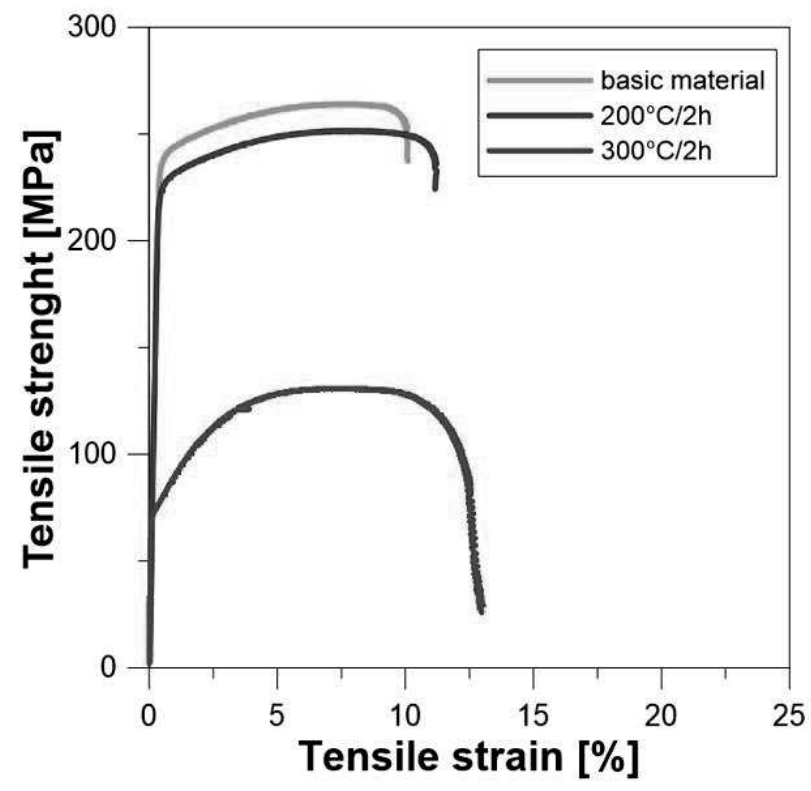

7). This is attributed to the increase of the grain size and coarsening of precipitates and intermetallic phases. Generally, such behaviour is in good agreement with the Vickers hardness measurements.



Fig. 7 Tensile stress-strain curves for studied material.

In practice, the ladder may be stressed at increased temperatures. Therefore, tensile tests were performed also at elevated temperatures $\left(100,150\right.$ and $\left.200{ }^{\circ} \mathrm{C}\right)$ on samples cut from a ladder beam. In this case, the reduction of values of TYS and UTS compared to the material tested at laboratory temperature was observed. It is known that mechanical properties of aluminium alloys are decreased at higher temperatures, due to the lower activation energies necessary for dislocation slip and easier overcoming of obstacles like precipitates. Such behaviour is more dominant at higher temperatures, therefore TYS and UTS are the most significantly reduced during loading at $200{ }^{\circ} \mathrm{C}$.

The main reason for the reduction of mechanical properties after increased temperatures is grain recrystallization and precipitation. The precipitates are incoherent and it impairs properties. These results have been reported by Panigrahi, S. K et al. [14]. During the increasing temperature, precipitates growth. It can be one of the problems with the strength of the material. F. Průša et al. [15] examined fracture surfaces and precipitates $\mathrm{Mg}_{2} \mathrm{Si}$ appeared at the edges of the fracture surfaces.

\section{Conclusions}

The increasing temperature has a crucial effect on microstructure and mechanical properties of firefighter ladders with beams composed of aluminium alloy 6063 and few other components (locks, welds) manufactured from other aluminium alloys. In the presented paper, it has been shown that the mechanical properties of samples obtained from ladder beams deteriorate after annealing at temperatures higher than 
$200{ }^{\circ} \mathrm{C}$. Huge decrease of TYS and UTS values was observed after annealing at $300{ }^{\circ} \mathrm{C}$ as a consequence of microstructure coarsening and overaged conditions. TYS values reached higher than $219 \mathrm{MPa}$ below the temperature of $200{ }^{\circ} \mathrm{C}$. After annealing at $300{ }^{\circ} \mathrm{C}$ led significant degradation of TYS to value $75 \mathrm{MPa}$. This behaviour was well documented by both tensile and hardness measurements. Also, welds were characterized by a steep decrease in mechanical properties after annealing at $300{ }^{\circ} \mathrm{C}$. A decrease in hardness was observed of more than 20 HV1.

The existence of brittle weld with the heat-affected zone suggests these areas as risky from the perspective of the fracture formation especially based on the specific thermal history of the ladder.

Besides, it is shown that loading of the ladder at increased temperatures has to be significantly reduced to prevent the fracture. The obtained results confirm a huge decrease in yield strength after exposure to temperature above $200{ }^{\circ} \mathrm{C}$.

\section{Acknowledgement}

\section{Authors wish to thank the Ministry of Interior (project: Safety improvement of extension ladders for}

firefighters - VI20162020021)

\section{References}

[1] JIANG, S., WANG, R. (2019). Grain size-dependent $\mathrm{Mg} / \mathrm{Si}$ ratio effect on the microstructure and mechanical/electrical properties of Al-Mg-Si-Sc alloys. Journal of Materials Science \& Technology 2019, 35 (7), 1354-1363.

[2] ALBERTO MUÑOZ, J., KOMISSAROV, A., AVALOS, M., et al. (2020). Heat treatment effect on an AA6063 alloy. Materials Letters 2020, 277, 128338.

[3] ZHONG, H., ROMETSCH, P. A., CAO, L., et al. (2016). The influence of $\mathrm{Mg} / \mathrm{Si}$ ratio and $\mathrm{Cu}$ content on the stretch formability of 6xxx aluminium alloys. Materials Science and Engineering: A 2016, 651, 688-697.

[4] DING, L., JIA, Z., ZHANG, Z., et al. (2015). The natural aging and precipitation hardening behaviour of Al-Mg-Si-Cu alloys with different $\mathrm{Mg} / \mathrm{Si}$ ratios and $\mathrm{Cu}$ additions. Materials Science and Engineering: A 2015, 627, 119-126.

[5] ASENSIO-LOZANO, J., SUÁREZ-PEÑA, B., VOORT, G. V. J. M. (2014). Effect of Processing Steps on the Mechanical Properties and Surface Appearance of 6063 Aluminium Extruded Products. 2014, 7, 4224 - 4242.
[6] SIDDIQUI, R. A., ABDULLAH, H. A., ALBELUSHI, K. R. (2000). Influence of aging parameters on the mechanical properties of 6063 aluminium alloy. Journal of Materials Processing Technology 2000, 102 (1), 234-240.

[7] YOUSEFI, A., EIVANI, A. R., BOUTORABI, S. M. A., et al. (2018). Effect of pre-deformation cooling rate on the age-hardening response of ultrafine grained AA6063. Materials Science and Engineering: A 2018, 713, 180-189.

[8] AYDI, L., KHLIF, M., BRADAI, C., et al. (2015). Mechanical Properties and Microstructure of Primary and Secondary AA6063 Aluminum Alloy after Extrusion and T5 Heat Treatment. Materials Today: Proceedings 2015, 2 (10, Part A), 4890-4897.

[9] GAVGALI, M., TOTIK, Y., SADELER, R. (2003). The effects of artificial aging on wear properties of AA 6063 alloy. Materials Letters 2003, 57 (24), 3713-3721.

[10] Ladder Injuries - Expert Introduction to Ladder Anatomy \& Accident Investigations. https://www.robsonforensic.com/articles/lad der-injuries-expert/.

[11] YAMAMOTO, N., LIAO, J., WATANABE, S., et al. (2009). Effect of intermetallic compound layer on tensile strength of dissimilar friction-stir weld of a high strength $\mathrm{Mg}$ alloy and $\mathrm{Al}$ alloy. Materials Transactions 2009, 50 (12), 2833-2838.

[12] SHAKOORI OSKOOIE, M., ASGHARZADEH, H., KIM, H. S. (2015). Microstructure, plastic deformation and strengthening mechanisms of an $\mathrm{Al}-\mathrm{Mg}-\mathrm{Si}$ alloy with a bimodal grain structure. Journal of Alloys and Compounds 2015, 632, 540-548.

[13] KUBASEK, J., VOJTECH, D., DVORSKY, D. (2017). Structure and Mechanical Properties of Aluminium Alloy Sampled from a Firefighter Ladder. Manufacturing Technology Joumal 2017, 17 (6), 876-881.

[14] PANIGRAHI, S. K., JAYAGANTHAN, R. (2010). Effect of annealing on precipitation, microstructural stability, and mechanical properties of cryorolled Al 6063 alloy. Journal of Materials Science 2010, 45 (20), 5624-5636.

[15] PRŮŠA, F., KUBÍČKOVÁ, D., JONÁK, V., et al. (2018). Firefighter Ladders Made of AA6063 Alloy Exposed to Elevated Temperatures and its Influence onto Mechanical Properties. 2018, 18 (5), 811-816. 